\title{
TERRITORIALIZAÇÃO EM SAÚDE: CONCEITOS, ETAPAS E ESTRATÉGIAS DE IDENTIFICAÇÃO
}

\section{TERRITORIALIZATION IN HEALTH: CONCEPTS, STAGES AND STRATEGIES OF IDENTIFICATION}

\author{
Anelise Pigatto Bissacotti \\ Graduanda em Nutrição pela Universidade Franciscana (UFN) \\ anelisebissacotti@yahoo.com \\ Ana Maria Gules \\ Graduanda em Nutrição e Farmácia pela Universidade Franciscana (UFN) \\ anamariagules@gmail.com \\ Adriane Cervi Blümke \\ Docente do Departamento de Alimentos e Nutrição do Curso de Nutrição \\ Universidade Federal de Santa Maria (UFSM) \\ adriblumke@yahoo.com.br
}

\begin{abstract}
RESUMO
Conhecer o território em que a Unidade de Saúde atua constitui-se em um elemento importante para a criação de estratégias que visem à melhoria dos serviços de saúde e do ambiente em que vivem a população. Para que essa identificação seja eficiente torna-se necessário buscar, criar e explorar ferramentas que auxiliem nesse processo. $\mathrm{O}$ objetivo desse trabalho foi resgatar os conceitos e as etapas para a territorialização em saúde e as estratégias para a sua realização. Conduziu-se um levantamento nas bases de dados google acadêmico e Lilacs, bibliografias acadêmicas e sites institucionais. Constatou-se a existência de vários conceitos de território e vários instrumentos para a realização da territorialização em saúde com ou sem uso de tecnologias, tais como: questionários, mapas, maquetes e sistemas informatizados. Esses instrumentos auxiliam no processo de planejamento e execução de atividades em cada etapa do processo de conhecimento do território e da população que nele habita. Dessa forma, a territorialização permite reorganizar as práticas em saúde pautadas na humanização da atenção e nas necessidades da comunidade.
\end{abstract}

Palavras-chave: Territorialidade. Território. Saúde. Saúde Pública. Unidade Básica de Saúde.

\begin{abstract}
Knowing the territory in which the Basic Health Unit works is a important element for the creation of strategies aimed at improving health services and the environment in which the population lives. In order for this identification to be efficient, it is necessary to seek out, create and explore tools to assist in this process. The objective of this research was to rescue the concepts and the stages for the territorialization in health and the strategies for its realization. A survey was conducted on Google Academic and Lilacs databases, academic bibliography and institutional websites. It was found the existence of various concepts of territory and various instruments for the realization of health territorialization with or without the use of technologies, such as questionnaires, maps, models and computerized systems. These instruments help in the process of planning and execution of activities at each stage of the process of knowledge of the territory and the population that inhabits it. Thus, territorialization allows the reorganization of health practices based on the humanization of care and the needs of the community.
\end{abstract}

Keywords: Territoriality. Territory. Public Health. Health resources. Basic Health Centers.

Recebido em: 26/02/2019

Aceito para publicação em: 12/09/2019 


\section{INTRODUÇÃO}

Um dos direitos básicos do ser humano é o acesso à saúde, a qual é garantida na Constituição Federal de 1988 (BRASIL, 2012). A saúde, além de ser um bem universal, é um dever do Estado (BRASIL, 2012), que, da mesma forma, é responsável pela organização dos serviços em saúde, conforme o território (FARIA, 2013) onde a Unidade Básica de Saúde está inserida. Assim, a saúde está diretamente relacionada com o território e depende da forma com que os serviços em saúde, os equipamentos sociais e as diversas instituições públicas e estabelecimentos estão projetados e organizados nele (FARIA, 2013).

Apesar do termo "território" referir-se a um "pedaço de terra" (GONDIM; MONKEN, 2009), apresenta um significado mais amplo no campo da saúde. O território é entendido como um espaço definido e delimitado por e a partir do poder (SOUZA, 1995). Quando, em um mesmo espaço, há várias relações de poder dá-se o nome de territorialidades e ao abrigar, em uma área, várias territorialidades pode ser considerado vários territórios. O termo ter ritorialização, quando empregado no planejamento de ações estratégicas de saúde, refere-se a uma ferramenta metodológica que possibilita o reconhecimento das condições de vida e da situação de saúde da população da área de abrangência de uma Estratégia Saú de da Família (ESF) (GONDIM; MONKEN, 2009) por meio da construção de um modelo de assistência voltado à realidade social (SILVA et al., 2001).

No entanto, para se construir um modelo de assistência pautado na necessidade local e na integralidade da atenção é necessário conhecer e compreender as distintas relações sociais, as quais são permeadas pelas condições econômicas, sociais, culturais, de saúde e de vida de uma população, bem como identificar os atores sociais e a sua íntima relação com os espaços e lugares de um território (MONKEN; BARCELLOS, 2007). Assim, por meio da caracterização da população e a identificação dos seus problemas de saúde e necessidades peculiares do território pode-se avaliar os efeitos dos serviços sobre os níveis de saúde (MONKEN; BARCELLOS, 2005; SANTOS; RIGOTTO, 2011). Para isso, deve-se investigar e explorar as condições de vida e o acesso à saúde da população no território. Contudo, no que diz respeito a territorialização, tem-se evidenciado que as bibliografias que abordam esse tema não dão suporte suficiente para os profissionais da saúde planejarem e executarem atividades de forma efetiva, durante o processo de conhecimento do território. Diante do exposto, esta pesquisa teve por objetivo resgatar os conceitos e as etapas para a territorialização em saúde e as estratégias para a sua realização.

Visando dar subsídio, aos profissionais da saúde, para a compreensão do processo de territorialização e a sua realização, o desenvolvimento deste estudo contempla, de forma didática, as seções: Conceitos; Origem do processo de territorialização em saúde coletiva; Territorialização: etapas e importância no planejamento em saúde; Instrumentos de aplicabilidade de territorialização em saúde.

A seção "Conceitos", permite compreender o significado do termo "território" em saúde. A "Origem do processo de territorialização em saúde coletiva" trata, brevemente, da inserção da territorialização na organização da Atenção Primária à Saúde (APS) e no planejamento das ações das Unidades Básicas de Saúde e da ESF. A "Territorialização: etapas e importância no planejamento em saúde" apresenta as etapas do processo de territorialização, assim como o detalhamento de cada uma, por meio da indicação dos dados a serem obtidos, onde e como coletá-los e a relevância dos mesmos. Além disso, a seção ressalta a importância da territorialização para a definição das ações a serem desenvolvidas pela Unidade Básica de Saúde e a ESF, com vista no atendimento das necessidades da comunidade atendida pela mesma. Na seção "Instrumentos de aplicabilidade de territorialização em saúde" são sugeridos alguns recursos e modelos que auxiliam na obtenção de informações sobre o território.

\section{METODOLOGIA}

A pesquisa consiste em uma revisão bibliográfica com abordagem narrativa e do tipo descritiva e documental, na qual foi realizado o resgate dos conceitos e das etapas para a 
territorialização em saúde e as estratégias para a sua realização, tendo em vista auxiliar os profissionais a compreenderem esse processo para a organização dos serviços de saúde. Para o desenvolvimento do estudo fez-se uso, como fonte de pesquisa, as plataformas digitais Google Acadêmico e Literatura Latino-Americana e do Caribe em Ciências da Saúde (Lilacs), empregando-se os seguintes descritores: "territorialização", "territorialização em saúde", "atenção básica", "vigilância em saúde" e "sistema de saúde". Além das plataformas digitais, foram consultadas bibliografias acadêmicas e sites de instituições estaduais e federais relacionadas a saúde, como o Ministério da Saúde (MS). Foram incluídos na pesquisa os artigos publicados em português e que apresentavam os descritores citados. Não houve restrição de período na seleção dos artigos utilizados na pesquisa.

Os dados encontrados foram descritos na forma de texto, no qual foram discutidos os principais conceitos envolvidos no processo de territorialização, entre eles: conceitos de espaço, território, territorialidade e territorialização, sua função na saúde, importância e aplicabilidade. Além dos conceitos, foi elaborado um quadro síntese com as principais etapas necessárias para operacionalizar a territorialização em saúde. A pesquisa foi desenvolvida no período de março a dezembro de 2016.

\section{DESENVOLVIMENTO}

\section{Conceitos}

$\mathrm{Na}$ contemporaneidade, a problematização sobre a abordagem das práticas na Atenção Básica à Saúde perpassa pela noção de espaço, território, territorialidade e territorialização. A noção de território atende aos preceitos de regionalização, hierarquização e descentralização propostos no Artigo 198, na Constituição de 1988, ao estruturar o Sistema Único de Saúde (SUS). Longe de teorias estanques, a efetivação e transformação da saúde, requer planejamento local e a associação entre poder público e participação social. É nesse cenário que se visualiza uma população específica, vivendo em tempo e espaço determinados, com problemas de saúde definidos e que interage com distintas unidades prestadoras de serviços de saúde (UNGLERT, 1993).

O espaço quando é analisado sob a luz de diversas ciências pode assumir variadas acepções e numerosos qualificativos. Para a geografia, enquanto ciência social, a expressão espaço geográfico ou somente espaço é vaga quando associada a porção da superfície da terra identificada pela natureza, pelo homem que ali imprimiu sua marca ou somente por ser um referencial de localização (CORRÊA, 1995). A partir de outras teorias, Santos (1985) contribuiu de forma positiva ao enunciar que o espaço deve ser analisado considerando-se categorias como: estrutura, processo, função e forma do mesmo que quando analisados em conjunto podem embasar uma teoria sobre os fenômenos espaciais. Os conceitos de espaço e sociedade se inter-relacionam, assim, uma sociedade só se torna concreta através de seu espaço e do espaço que ela produz e, por outro lado, o espaço só é inteligível através da sociedade (CORRÉA, 1995). O espaço representa muito mais que uma superfície geográfica, tendo um perfil demográfico, epidemiológico, administrativo, tecnológico, político e social que o caracteriza e se expressa num território em permanente construção.

O território forma-se a posteriori a partir das relações de poder que se estabelecem num determinado espaço (GIL; FERNANDES, 2005). O termo território pode ser associado a pelo menos duas origens: a primeira significa "terra pertencente a", ou seja, terri (terra) e torrium (pertence a), de origem latina; a segunda, associada a primeira, térreo-territor (aterrorizar aquele que aterroriza) designou a concepção política de quem aterroriza para dominar e de quem é aterrorizado pelo domínio de uma determinada porção do espaço (HAESBAERT, 2004). O território é carregado de intencionalidades, que se manifestam no espaço. A intenção das pessoas ao escolherem um lugar ou optarem por ficar onde estão, imprimindo nele uma paisagem que reflete essas intenções, corresponde ao território (GIL; FERNANDES, 2005). Pressupõe-se que a ideia de território consiste na relação de poder seja técnico, econômico, social, político ou cultural, proveniente das relações interpessoais ou com a natureza, refletindo a realidade de determinado tempo e espaço. Na tradicional Geografia Política, o 
território surge como o espaço concreto em si (com seus atributos naturais e socialmente construídos) que é apropriado, ocupado, por um grupo social.

No processo de implantação das equipes de Unidades Básicas e Saúde da Família, o município pode ser dividido em vários territórios. Cada território possui peculiaridades em respeito a seus usuários e suas equipes, à sua capacidade de estrutura física e recursos financeiros, organização social, conflitos e contradições inerentes ao local em que se encontra inserido (BRASIL, 2009). Segundo Mendes (2011), em saúde, os territórios podem ser:

- Território-distrito: Delimita um território administrativo assistencial, contendo um conjunto de pontos de atenção à saúde e uma população adscrita. Visa aproximar poder administrativo público e comunidade.

- Território-área: corresponde à área de atuação de uma ou no máximo três equipes de saúde. Com enfoque na vigilância à saúde, planeja as ações, organiza os serviços e viabiliza os recursos para o atendimento das necessidades dos usuários residentes no te rritório.

- Território microárea: é uma subdivisão do território-área, corresponde à área de atuação de um Agente Comunitário em Saúde (ACS).

Por consequência entende-se que territorialidade é a "razão de ser" dos territórios, conferindoIhes existência, seja material ou imaterial (MOYSÉS; SÁ, 2014), ou seja, consiste na manutenção do mesmo preservando-o por meio do equilíbrio entre as sociedades e a natureza. Para Raffestin (1993) a territorialidade é composta por três elementos: senso de identidade espacial, senso de exclusividade e compartimentação da interação humana no espaço. E ainda, a territorialidade seria um conjunto de relações que se originam num sistema tridimensional, sociedade - espaço - tempo, em vias de atingir a maior autonomia possível, compatível com os recursos do sistema (RAFFESTIN, 1993).

A relação de alguns preceitos básicos discorridos é indispensável no entendimento do processo de territorialização em saúde. A territorialização é uma ferramenta importante no planejamento dos serviços de saúde pública, tanto para avaliar quanto para implantar novos projetos. Em outras palavras, o processo de territorialização viabiliza um diagnóstico mais preciso da comunidade. Essa tarefa adquire, no entanto, ao menos três sentidos diferentes e complementares: de demarcação de limites das áreas de atuação dos serviços; de reconhecimento do ambiente, população e dinâmica social existente nessas áreas; e de estabelecimento de relações horizontais com outros serviços adjacentes e verticais com centros de referência (PEREIRA; BARCELLOS, 2006). Para Fuini (2014) a territorialização significa ação, movimento ou processo de construção e criação de territórios pela apropriação, uso, identificação, enraizamento com determinadas extensões do espaço por lógicas políticas, econômicas ou culturais, sendo também sinônimo de qualificação ou organização territorial. Esse foi o modo encontrado para se resolver a questão da definição das áreas de atuação dos serviços de Atenção Primária à Saúde, ou seja, territorializando os serviços e cadastrando (adscrição de clientela, como é chamada) a população no seu interior (FARIA, 2013).

\section{Origem do processo de territorialização na saúde coletiva}

O processo de territorialização na saúde tem início na Constituição de 1988 com a criação do SUS. Desde sua concepção o SUS associa-se a perspectiva territorial por meio dos princípios organizativos de regionalização e descentralização das ações e serviços de saúde (GONDIM; MONKEN, 2009). Contudo o território não foi objeto principal de análise e planejamento durante a década de 1990. A dimensão territorial não foi incorporada à formulação de políticas durante o processo de descentralização em saúde na primeira década do SUS. Como consequência há uma fragilidade da lógica territorial na formulação de políticas públicas, com escassez de estratégias e instrumentos para atender aos objetivos da redução da iniquidade social e territorial; e os existentes não se articulam entre si (GADELHA et al., 2011).

Ainda segundo Gadelha et al. (2011), outros aspectos apontam para a fragilidade inicial da territorialização em saúde como o fato de que a descentralização dissociou-se de um projeto de regionalização nacional e as propostas de regionalização tiveram início tardio, após

DOl:http://dx.doi.org/10.14393/Hygeia153247115 Hygeia 15 (32): 41 - 53, junho/2019 página 44


sucessivos momentos de descentralização sob forte indução e regulação federal por meio de normas operacionais básicas e de assistência do SUS, levando a experiências limitadas de organização territorial das ações e serviços de saúde. Soma-se o fato de que com a municipalização os governos locais assumiram a responsabilidade pela provisão de serviços de saúde, num contexto em que a maioria dos municípios apresentava pequena base populacional e limitada capacidade institucional, o que por sua vez prejudicou a função de planejamento regional. Por fim, a concepção de regionalização tem se restringido às questões relativas à organização da rede de serviços, sem a incorporação de uma lógica territorial mais abrangente e a articulação com outras esferas da política pública.

Com o avanço do SUS, os serviços foram paulatinamente organizados de acordo com o nível de complexidade, população e localização geográfica (GONDIM et al., 2008). Nesse sentido, com a implantação e fortalecimento da APS ao longo desses anos, houve um avanço na compreensão do território e na utilização da metodologia de territorialização em saúde para fins de análise e planejamento em saúde, contudo ainda de forma insipiente principalmente na formulação de políticas públicas. Desde 994, com a criação do Programa Saúde da Família (PSF), considerado uma estratégia de consolidação do SUS, e sob influência da Organização Pan-Americana da Saúde (OPAS), a territorialização na Atenção Primária à Saúde no Brasil é considerada como política, pois foi sugerida pelo Estado, visando auxiliar na organização da APS e como uma técnica de planejamento, contribuindo para a delimitação das áreas de atuação das Unidades Básicas de Saúde e das Equipes de Saúde da Família (FARIA, 2013).

Hoje a política nacional de saúde é construída com enfoque regional tendo como questão central a organização das ações e serviços no território. Um dos fundamentos da ESF é a Atenção Básica territorializada, construída sobre uma base territorial espacialmente delimitada e seguindo o modelo de adstrição da clientela. Nessa perspectiva, o território deve ser considerado um espaço vivo capaz de produzir saúde, e por isso um espaço dinâmico em constante transformação nos seus diversos aspectos como, história, demografia, cultura e epidemiologia. Assim, conhecer o processo de territorialização é fundamental no contexto da Atenção Básica ou Atenção Primária à Saúde, pois o mapeamento do território possibilita um atendimento sensível às necessidades da população (SANTOS; RIGOTTO, 2011).

\section{Territorialização: etapas e importância no planejamento em saúde}

Conhecer o território em que a Unidade Básica de Saúde atua é essencial, principalmente para a ESF. As condições sociais da população influenciam diretamente no processo saúdedoença e, dessa forma, a territorialização contribui para o planejamento de ações eficazes em saúde e voltadas ao atendimento das necessidades da população deste território (OLIVEIRA et al., 2007).

Para que ações em saúde sejam desenvolvidas, deve-se respeitar as etapas que a territorialização exige. Cada etapa que compõe o processo de territorialização permite 0 acesso, da equipe de saúde, às características do território e sua população (MÔRA et al., 2013). No quadro 1 encontra-se as dez etapas sugeridas para o processo de territorialização, as quais foram adaptadas de alguns autores (MENDES; DONATO, 2003; MONKEN; BARCELLOS, 2005; MÔRA et al., 2013; SILVA et al., 2001). Deve-se ressaltar que o território está em constante processo de transformação (território vivo) e isso implica na necessidade de as equipes de saúde manterem atualizados os dados do território (MENDES; DONATO, 2003). 
Quadro 1 - Etapas do processo de territorialização em saúde.

\begin{tabular}{|c|c|c|}
\hline \multicolumn{3}{|c|}{ 1ª etapa: Levantamento de informações já disponíveis sobre o território } \\
\hline Dados a serem obtidos & Onde e como & Importância \\
\hline $\begin{array}{l}\text { - Demográficos } \\
\text { - Socioeconômicos } \\
\text { - Saneamento } \\
\text { - Epidemiológicos }\end{array}$ & $\begin{array}{l}\text { Buscar dados junto: } \\
\text { - Ao Instituto Brasileiro de } \\
\text { Geografia e Estatística (IBGE) } \\
\text { - A Companhias de abastecimento } \\
\text { de água e esgoto, limpeza urbana } \\
\text { e energia elétrica } \\
\text { - Ao Departamento de Informática } \\
\text { do SUS (DATASUS) } \\
\text { - As Secretarias Estadual e } \\
\text { Municipal de Saúde, Educação e } \\
\text { Meio ambiente } \\
\text { - A Unidade Básica de Saúde } \\
\text { - Ao Conselho Local de Saúde }\end{array}$ & $\begin{array}{l}\text { - Facilita e orienta a pesquisa de } \\
\text { campo } \\
\text { - Evita custos desnecessários } \\
\text { - Evita duplicidade de dados }\end{array}$ \\
\hline \multicolumn{3}{|c|}{ 2a etapa: Reconhecimento do território } \\
\hline Dados a serem obtidos & Onde e como & Importância \\
\hline $\begin{array}{l}\text { - Topografia } \\
\text { - Condições e densidade das } \\
\text { habitações } \\
\text { - Saneamento básico } \\
\text { - Presença de lixo acumulado e } \\
\text { esgoto } \\
\text { - Atividade } \\
\text { predominante } \\
\text { - Localização da unidade de saúde } \\
\text { - Identificar os estabelecimentos } \\
\text { de interesse tais como escolas, } \\
\text { mercados, padarias, feiras, } \\
\text { farmácias } \\
\text { - Identificar as áreas de maior } \\
\text { risco social e ambiental }\end{array}$ & $\begin{array}{l}\text { - Realizar o passeio ambiental } \\
\text { - Conversar com alguns } \\
\text { moradores e donos de } \\
\text { estabelecimentos } \\
\text { - Fazer o registro de informações } \\
\text { por meio de foto e vídeo } \\
\text { - Elaboração da cartografia } \\
\text { participativa }\end{array}$ & $\begin{array}{l}\text { Essa etapa permite: } \\
\text { - identificar a população } \\
\text { - conhecer as necessidades dos } \\
\text { indivíduos } \\
\text { - identificar como o território se } \\
\text { insere na dinâmica da cidade } \\
\text { - verificar o(s) impactos dos } \\
\text { serviços de saúde sobre a } \\
\text { população } \\
\text { - estabelecer/fortalecer vínculo } \\
\text { entre serviços de saúde e } \\
\text { comunidade } \\
\text { - realizar o mapeamento das áreas } \\
\text { de risco }\end{array}$ \\
\hline \multicolumn{3}{|c|}{$3^{a}$ etapa: Levantamento de informações com informantes-chave por meio de entrevistas } \\
\hline Dados a serem obtidos & Onde e como & Importância \\
\hline $\begin{array}{l}\text { - Características da população } \\
\text { (cultura, condições de vida e de } \\
\text { saúde, segurança alimentar e } \\
\text { nutricional do domicílio, entre } \\
\text { outros) e da área em que habitam } \\
\text { - Histórico do local/comunidade }\end{array}$ & $\begin{array}{l}\text { Buscar auxílio com: } \\
\text { - pessoas que moram a mais } \\
\text { tempo na comunidade, tais como: } \\
\text { diretor(es)(as) e professor(es)(as) } \\
\text { de escola(s), líderes comunitários } \\
\text { (vinculados a associações, igrejas, } \\
\text { pastoral da saúde, etc.) }\end{array}$ & $\begin{array}{l}\text { - Baixo custo } \\
\text { - Permite o contato com pessoas } \\
\text { da comunidade } \\
\text { - Facilita o acesso à informações }\end{array}$ \\
\hline \multicolumn{3}{|c|}{ 4a etapa: Reconhecimento dos estabelecimentos de interesse para a saúde } \\
\hline Dados a serem obtidos & Onde e como & Importância \\
\hline $\begin{array}{l}\text { - Funcionamento e características } \\
\text { dos estabelecimentos (mercados, } \\
\text { mini-mercados, padarias, comércio } \\
\text { em geral, farmácias, consultórios } \\
\text { entre outros) } \\
\text { - Características da população que } \\
\text { utiliza o serviço }\end{array}$ & $\begin{array}{l}\text { - Visita in loco } \\
\text { - Utilizar entrevistas por meio de } \\
\text { um roteiro, sendo importante } \\
\text { gravar e também registrar as } \\
\text { informações (fotos e vídeos) }\end{array}$ & $\begin{array}{l}\text { Permite: } \\
\text { - identificar as necessidades de } \\
\text { intervenção em saúde, em } \\
\text { alimentação e nutrição e em } \\
\text { segurança alimentar e nutricional }\end{array}$ \\
\hline \multicolumn{3}{|c|}{ 5a etapa: Reconhecimento da unidade básica de saúde } \\
\hline Dados a serem obtidos & Onde e como & Importância \\
\hline $\begin{array}{l}\text { - № de funcionários e profissionais } \\
\text { da saúde } \\
\text { - Serviços prestados } \\
\text { - Capacidade e dinâmica de } \\
\text { atendimento } \\
\text { - Principais demandas } \\
\text { - Horário e funcionamento do } \\
\text { serviço }\end{array}$ & $\begin{array}{l}\text { - Visita in loco } \\
\text { - Observação, entrevistas } \\
\text { registro das informações }\end{array}$ &  \\
\hline
\end{tabular}




\begin{tabular}{|c|c|c|}
\hline $\begin{array}{l}\text { - Processo de trabalho } \\
\text { - Ações de promoção da saúde }\end{array}$ & & \\
\hline \multicolumn{3}{|c|}{$6^{\text {a }}$ etapa: Organização e análise dos dados obtidos } \\
\hline Dados a serem obtidos & Onde e como & Importância \\
\hline ( & $\begin{array}{l}\text { - Tabulação dos dados de forma } \\
\text { descritiva, com tabelas, gráficos e } \\
\text { figuras } \\
-\quad \text { Interpretar e discutir as } \\
\text { informações obtidas } \\
\text { - Analisar o resultado encontrado }\end{array}$ & $\begin{array}{l}\text { - Evita erros, equívocos e perda de } \\
\text { informações } \\
\text { - Identificação de falhas e/ou } \\
\text { carências nos serviços de saúde e } \\
\text { necessidades da população } \\
\text { - Sugestão de ações corretivas }\end{array}$ \\
\hline \multicolumn{3}{|c|}{$7^{\text {a }}$ etapa: Espacialização dos dados } \\
\hline Dados a serem obtidos & Onde e como & Importância \\
\hline NA & $\begin{array}{l}\text { - Espacializar os dados pode ser } \\
\text { feito mediante a confecção de } \\
\text { mapas (mapa inteligente, falante, } \\
\text { digital) ou maquetes }\end{array}$ & - Facilita a interpretação dos dados \\
\hline \multicolumn{3}{|c|}{ 8ª etapa: Planejamento de ações } \\
\hline Dados a serem obtidos & Onde e como & Importância \\
\hline NA & $\begin{array}{l}\text { - Definir metas e objetivos } \\
\text { - Planejar ações estratégicas para } \\
\text { a comunidade em cada meta, com } \\
\text { foco na realidade e nos principais } \\
\text { problemas identificados } \\
\text { - Elaborar projetos com foco na } \\
\text { intersetorialidade e ações } \\
\text { concretas na comunidade }\end{array}$ & $\begin{array}{l}\text { - Evita imprevistos } \\
\text { - Contribui para a futura realização } \\
\text { de ações eficientes } \\
\text { - Melhora das condições de vida e } \\
\text { de saúde da população do } \\
\text { território no longo prazo }\end{array}$ \\
\hline \multicolumn{3}{|c|}{ 9ª etapa: Execução das ações em saúde } \\
\hline Dados a serem obtidos & Onde e como & Importância \\
\hline NA & $\begin{array}{llr}\text { - Pôr em } & \text { prática as } \\
\text { ações/estratégias } & \text { planejadas } \\
\text { conforme } & \text { metodologias } \\
\text { previamente estabelecidas }\end{array}$ & $\begin{array}{l}\text { - Promoção de saúde } \\
\text { - Prevenção de doenças } \\
\text { - Satisfação dos usuários } \\
\text { - Melhoria na atenção em saúde }\end{array}$ \\
\hline \multicolumn{3}{|c|}{ 10 etapa: Verificação da eficiência das ações em saúde } \\
\hline Dados a serem obtidos & Onde e como & Importância \\
\hline $\begin{array}{l}\text { Estratégias que foram mais } \\
\text { eficientes nas ações em saúde }\end{array}$ & $\begin{array}{l}\text { - Verificar o impacto das ações } \\
\text { e/ou satisfação dos usuários do } \\
\text { território }\end{array}$ & $\begin{array}{l}\text { - Identificação de falhas e/ou } \\
\text { carências nos serviços de saúde } \\
\text { - Identificação de necessidades da } \\
\text { população } \\
\text { - Sugestão de ações corretivas }\end{array}$ \\
\hline
\end{tabular}

NA - Não se aplica

\section{Instrumentos de aplicabilidade de territorialização em saúde}

A obtenção e gerenciamento de dados no processo de territorialização podem ser desenvolvidos com instrumentos simples, usados junto à comunidade, até tecnologias mais apuradas. Convém iniciar delimitando a macroárea do território sanitário e, depois, as microáreas das quais é composto. Sugere-se abaixo alguns recursos e modelos a serem utilizados.

a) Identificar a existência do plano diretor municipal que contenha um mapa-base de identificação do território.

b) Buscar dados demográficos e epidemiológicos que sirvam de base para o início da pesquisa ou como comparativo com os novos dados. Pode-se usar como fonte os dados disponíveis no Instituto Brasileiro de Geografia e Estatística (IBGE), Departamento de Informática do SUS (DATASUS), Secretarias Municipais e Estaduais de Saúde, Educação, Meio Ambiente e outras.

c) Uso de questionários que possam ser aplicados em diferentes áreas e serviços e com diferentes pessoas do território a ser mapeado. O perfil dos entrevistados deve ser o mais diversificado possível, abrangendo, por exemplo, indivíduos de diferentes classes sociais, ocupações e níveis de escolaridade. Como não há questionários específicos para serem utilizados 
no processo de territorialização, criou-se sugestões, as quais podem ser visualizadas nos quadros 2, 3, 4 e 5. Os questionários sugeridos permitem o conhecimento do território, da Unidade de Saúde, dos estabelecimentos de interesse para a saúde e das condições de vida dos usuários.

Quadro 2 - Questionário para o conhecimento do território em que a Unidade Básica de Saúde/Estratégia Saúde da Família está inserida.

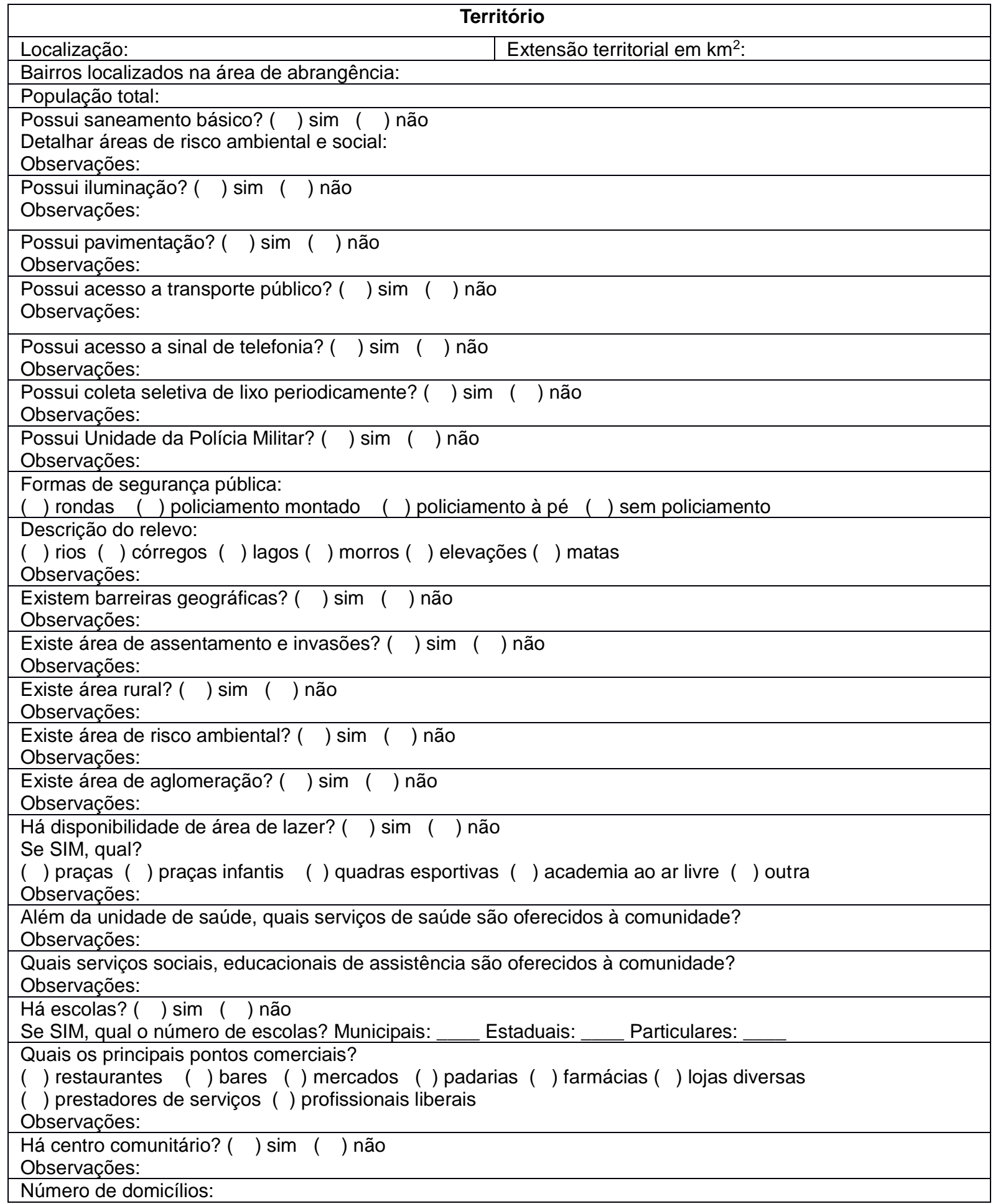




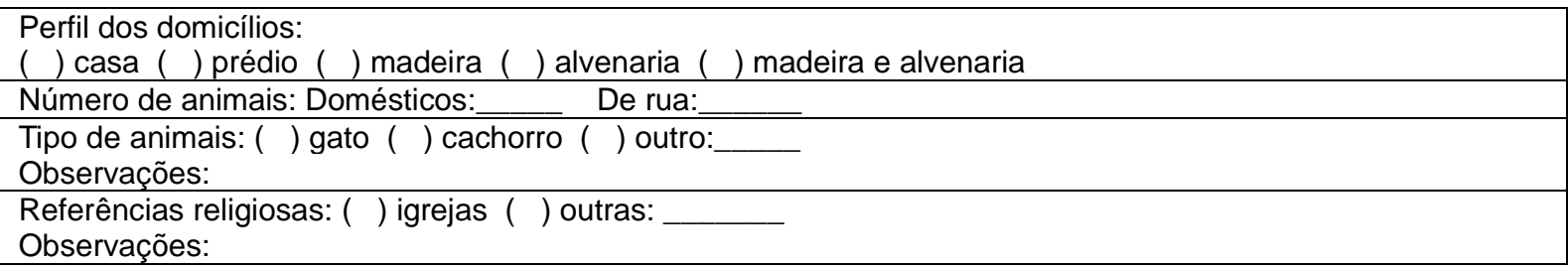

Quadro 3 - Questionário de conhecimento da Unidade Básica de Saúde/Estratégia Saúde da Família.

\begin{tabular}{|c|c|c|c|}
\hline \multicolumn{4}{|c|}{ Unidade Básica de Saúde (UBS) } \\
\hline \multicolumn{4}{|l|}{ Nome da UBS: } \\
\hline \multicolumn{4}{|l|}{ Endereço: } \\
\hline \multicolumn{2}{|l|}{ Bairro: } & \multicolumn{2}{|l|}{ Região: } \\
\hline \multicolumn{4}{|l|}{ Acesso a UBS: } \\
\hline \multicolumn{4}{|l|}{ Telefone: } \\
\hline \multicolumn{4}{|l|}{ Horário de funcionamento: } \\
\hline \multicolumn{2}{|l|}{ Tipologia (ESF, EACS...): } & \multicolumn{2}{|c|}{ Número de usuários cadastrados: } \\
\hline \multicolumn{4}{|l|}{ Histórico da UBS: } \\
\hline \multicolumn{4}{|l|}{ Área física: } \\
\hline \multicolumn{4}{|l|}{ Área externa: } \\
\hline \multicolumn{4}{|l|}{ Perfil da construção: } \\
\hline \multicolumn{4}{|c|}{ Número de salas conforme função: } \\
\hline \multicolumn{4}{|c|}{ Equipamentos disponíveis: } \\
\hline \multicolumn{4}{|l|}{ Categorias profissionais: } \\
\hline Profissionais & Especialidade & $\begin{array}{c}\text { Carga horária de } \\
\text { trabalho }\end{array}$ & Tempo de atuação \\
\hline \multicolumn{4}{|l|}{ Serviços oferecidos: } \\
\hline \multicolumn{4}{|l|}{ Projetos implantados: } \\
\hline \multicolumn{4}{|c|}{ Levantamento sobre o perfil dos usuários: } \\
\hline \multicolumn{4}{|c|}{ Principais patologias apresentadas pelos usuários: } \\
\hline \multicolumn{4}{|c|}{ Relação com as lideranças comunitárias: } \\
\hline \multicolumn{4}{|c|}{ Aspectos positivos da UBS: } \\
\hline \multicolumn{4}{|l|}{ Aspectos negativos da UBS: } \\
\hline \multicolumn{4}{|c|}{ Dificuldades da UBS: } \\
\hline \multicolumn{4}{|c|}{$\begin{array}{l}\text { Reuniões de planejamento de equipe: } \\
\text { Coordenação: }\end{array}$} \\
\hline Coordenação: & & & \\
\hline
\end{tabular}

Quadro 4 - Questionário de conhecimento dos estabelecimentos de interesse para a saúde.

\begin{tabular}{|c|c|}
\hline \multicolumn{2}{|c|}{ Estabelecimentos de interesse em saúde } \\
\hline Tipo de estabelecimento & $\begin{array}{l}\text { Número e descrição dos estabelecimentos no território em } \\
\text { avaliação }\end{array}$ \\
\hline ( ) escola & \\
\hline ( ) padaria & \\
\hline ( ) açougue & \\
\hline ( ) mini mercado & \\
\hline ( ) supermercado & \\
\hline ( ) venda & \\
\hline ( ) feira & \\
\hline ( ) restaurante & \\
\hline ( ) restaurante popular & \\
\hline ( ) cozinha comunitária & \\
\hline ( ) banco de alimento & \\
\hline
\end{tabular}




\begin{tabular}{|l|l|}
\hline ( $)$ farmácias, consultórios, clínicas & \\
\hline ( $)$ entidades/associações/ONGs & \\
\hline ( $)$ outro & Perfil do estabelecimento \\
\hline & Nome do estabelecimento: \\
\hline Ramo: \\
( $\quad$ alimentício \\
( $\quad$ saúde \\
( ) educacional \\
Condições do estabelecimento: Qual? \\
Tem potencial para ações em saúde? Quais ações? Que público-alvo irá abranger? \\
\hline Endereço: \\
\hline Horários de funcionamento: \\
\hline Responsável: \\
\hline Número de funcionários: \\
\hline Clientela: \\
( ) moradores do bairro \\
( ) moradores de outros bairros \\
( ) pessoas de outros municípios \\
( ) outros. Qual?
\end{tabular}

Quadro 5 - Questionário para conhecimento das condições de vida do usuário da Unidade Básica de Saúde/Estratégia Saúde da Família.

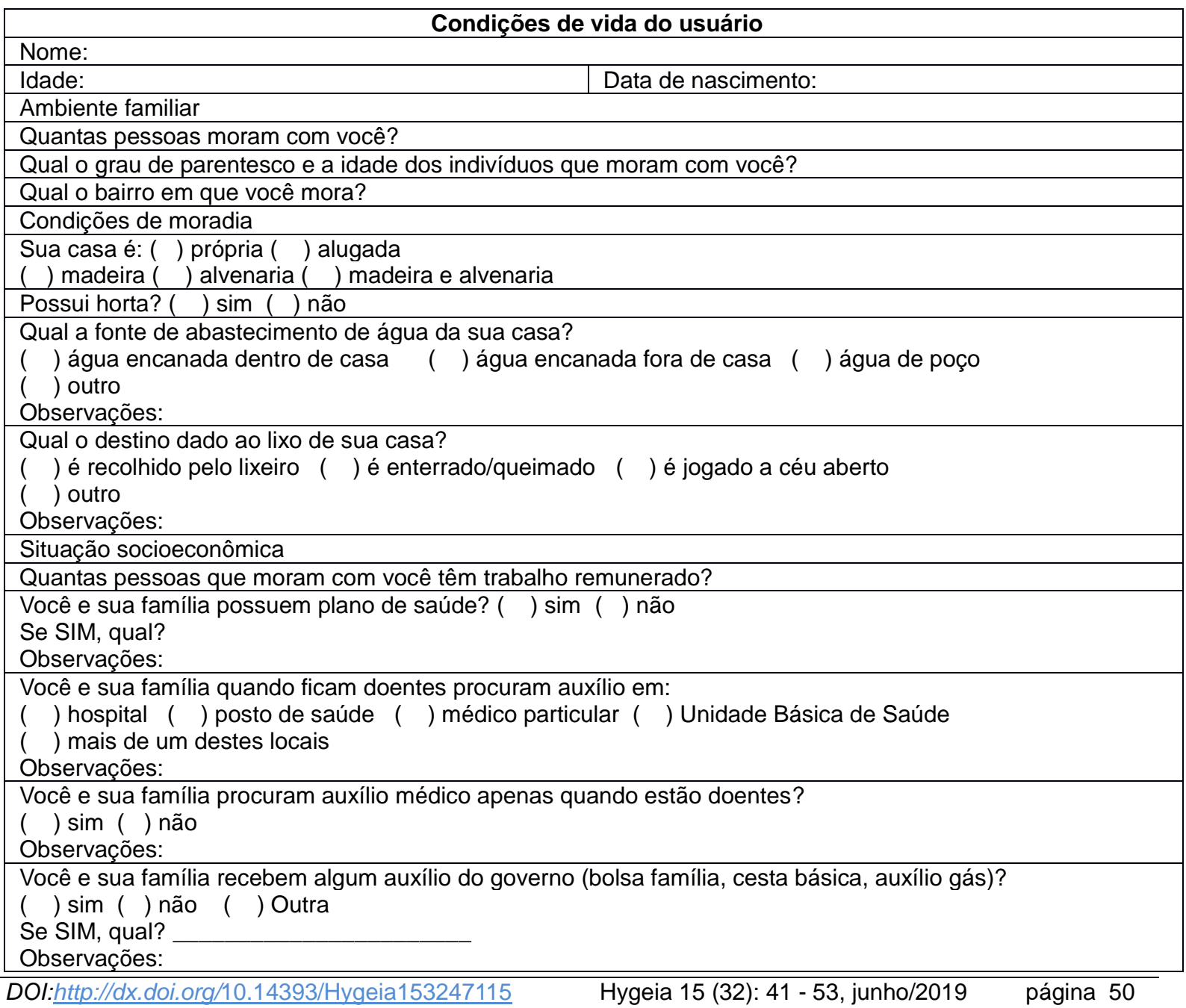




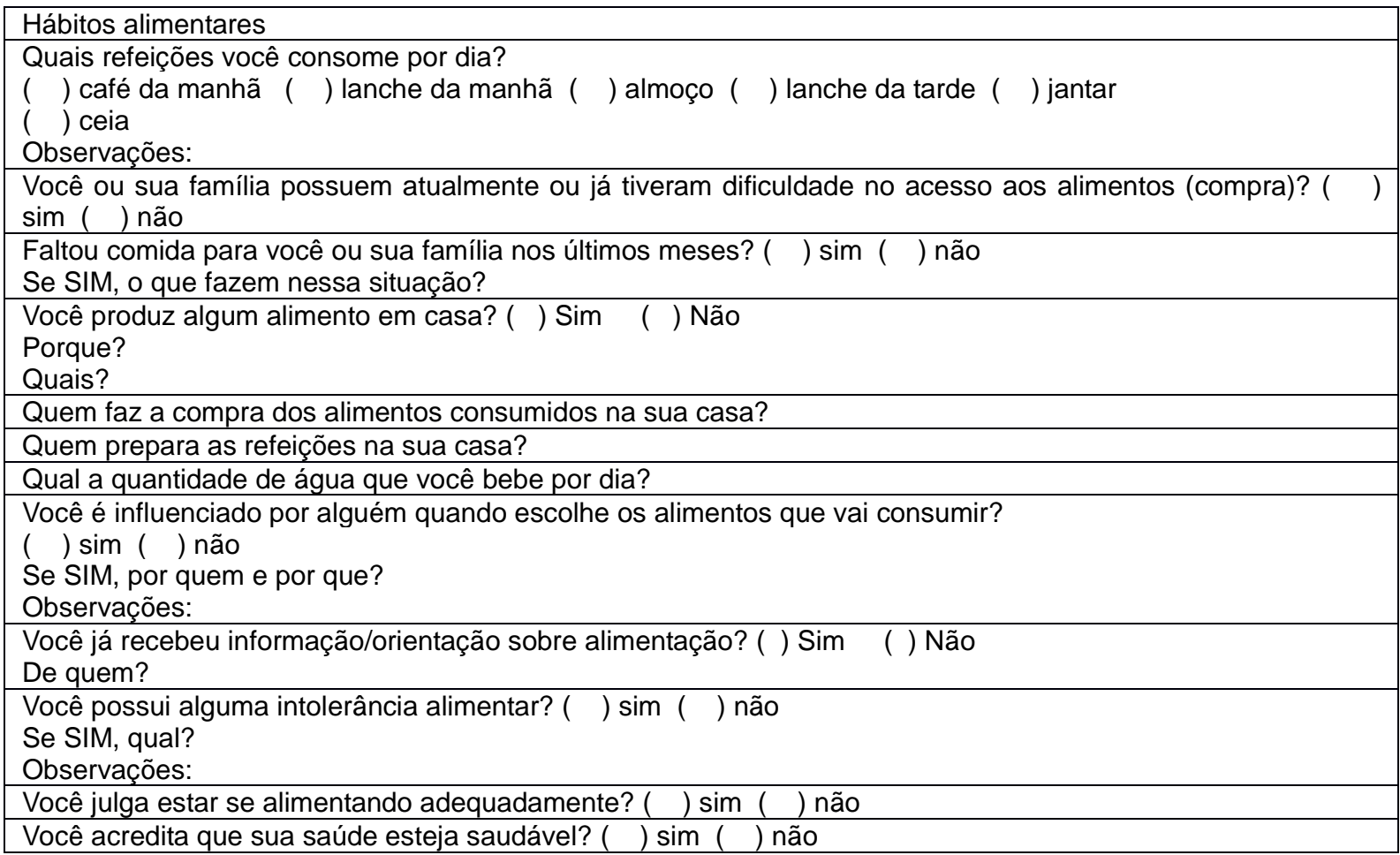

d) Utilização de imagens como, por exemplo, fotos e vídeos de diversas áreas da comunidade para ilustrar a realidade vivida.

e) Elaboração de maquetes, mapas e mapa-falante para espacializar as informações disponíveis do território.

f) Utilização do geoprocessamento, que na área de saúde tem evoluído com as inovações em informática. Dada à oferta de programas, é possível fazer o mapeamento digital organizando dados dos usuários, dados espaciais (geográficos e cartográficos) e produzindo mapas temáticos com maior fidelidade. Atualmente destacam-se algumas ferramentas como, por exemplo, módulos de mapeamento no software Tabwin (DATASUS), plataforma no ambiente Terraview (Instituto Nacional de Pesquisas Espaciais - INPE) e as ferramentas Google como Google Maps e Google Street View. Além disso, existem uma série de materiais instrucionais explicativos do processo de Geoprocessamento como "Sistemas de Informação Geográfica e a Gestão da Saúde no Município" e os livros "Conceitos Básicos de Sistemas de Informação Geográfica e Cartografia Aplicados à Saúde" e "Sistemas de Informação Geográfica - Conceitos Básicos" (BRASIL, 2006).

Com base nos dados da análise do território procede-se a última etapa da territorialização em saúde, a qual consiste no planejamento de ações. A ações a serem planejadas devem ser pautadas na realidade encontrada, a qual a traz como potencial o alinhamento dos serviços de saúde do Sistema Único de Saúde com os demais serviços e políticas públicas do território que favoreçam a construção de ambientes saudáveis. Dessa forma, a territorialização em saúde pode contribuir para mapear as necessidades de implantação e reforço das ações de vigilância em saúde e segurança alimentar e nutricional objetivando a promoção da saúde no território, articulando intersetorialmente com diferentes instituições, setores e equipamentos, com vistas a propiciar a saúde da população.

Para tanto, o treinamento da equipe que fará o levantamento dos dados, um bom planejamento do roteiro a ser seguido, o uso de instrumentos como questionários e a manutenção de uma rede informatizada e atualizada de dados, otimizam a operacionalização da territorialização e permitem o acompanhamento e a avaliação objetiva das ações propostas. 


\section{CONSIDERAÇÕES FINAIS}

A Constituição Federal de 1988 legitima os princípios da universalidade, equidade e integralidade que ancoram o Sistema Único de Saúde. Destaca-se, assim, a relevância do processo de territorialização em saúde, bem como dos conceitos que o mesmo abarca, por elencar especificidades significativas no entendimento da relação saúde-doença. A territorialização, na sua aplicabilidade, emana do todo ao particular, possibilitando formular um diagnóstico mais preciso e projetar ações mais eficazes. Promove o entendimento dos riscos e agravantes da saúde de uma determinada população. A coleta e análise de dados por critérios geográficos possibilita a atualização de dados demográficos, epidemiológicos, criando laços significativos ao oferecer serviços em saúde que atendam as carências do território mapeado. Além disso, sua importância ultrapassa o âmbito da saúde ao conferir, à determinada comunidade, a cidadania necessária à reflexões de foro político, social e cultural. No momento atual, a reorganização das práticas em saúde pública e coletiva, perpassam pelo entendimento humanizado do território, pautadas na alteridade e no reconhecimento do outro como cidadão sujeito de suas vontades, substituindo posições tecnicistas e objetivistas que, por vezes, ainda perduram. Ademais, existem modelos como a territorialização coletiva ou método participativo de territorialização e oportunidades para se empregar a territorialização em saúde ainda pouco exploradas, como por exemplo, na organização do processo de matriciamento das equipes do Núcleo de Apoio a Saúde da Família (NASF), na estruturação das linhas de cuidados, na definição de estratégias de atendimento na rede de saúde do SUS, em especial na média e alta complexidade e na condução do processo de trabalho eficaz e efetivo de programas como o Saúde na Escola e Bolsa Família.

\section{REFERÊNCIAS}

ALMEIDA, R. F. et al. O processo de territorialização realizado pelos alunos do curso de medicina da UESB entre agosto de 2004 e janeiro de 2005. Revista Saúde.Com, Itapetinga, v. 3, n. 1, p. 64-74, 2007.

BRASIL. Constituição da República Federativa do Brasil. 35. ed. Brasília: Câmara dos Deputados, Edições Câmara, 2012.

BRASIL. Ministério da Saúde. O sUS de A a Z: garantindo saúde nos municípios. Brasília: Editora do Ministério da Saúde, 2009.

BRASIL. Abordagens espaciais na saúde pública. Brasília: Ministério da Saúde, 2006.

CORRÊA, R. L. Espaço, um conceito-chave da geografia. In: CASTRO, I. E.; GOMES, P. C. da C.; CORRÊA, R. L. Geografia: conceitos e temas. Rio de Janeiro: Editora Bertrand, 1995. p. 15-47.

FARIA, R. M. de. A territorialização da atenção primária à saúde no Sistema Único de Saúde e a construção de uma perspectiva de adequação dos serviços aos perfis do território. Hygeia, Uberlândia, v. 9, n. 16, p. 131-147, 2013.

FUINI, L. L. Território, territorialização e territorialidade: o uso da música para a compreensão de conceitos geográficos. Terra@Plural, Ponta Grossa, v. 8, n. 1, p. 225-249, 2014. https://doi.org/10.5212/TerraPlural.v.8i1.0012

GADELHA, C. A. G.; MACHADO, C. V.; LIMA, L. D.; BAPTISTA, T. W. F. Saúde e territorialização na perspectiva do desenvolvimento. Ciência \& Saúde Coletiva, v. 16, n. 6, p. 3003-3016, 2011. https://doi.org/10.1590/S1413-81232011000600038

GIL, I. C.; FERNANDES, B. M. Regiões contidas e desenvolvimento territorial: uma reflexão sobre o desenvolvimento contemporâneo da Nova Alta Paulista. Revista Nera, Presidente Prudente, n. 6, p. 75-91, 2005.

GONDIM, G. M. de M. et al. O território da saúde: A organização do sistema de saúde e a territorialização. In: MIRANDA, A. C. de et al. (Org.). Território, Ambiente e Saúde. 1. ed. Rio de Janeiro: FIOCRUZ, 2008. p. 237-255. 
GONDIM, G. M. de M.; MONKEN, M. Territorialização em saúde. Rio de Janeiro: Rio de Janeiro, 2009.

HAESBAERT, R. O mito da desterritorialização: do "Fim dos Territórios" à Multiterritorialidade. Rio de Janeiro: Editora Bertrand, 2004.

MENDES, E. V. As redes de atenção à saúde. Brasília: OPAS, 2011.

MENDES, R.; DONATO, A. F. Território: espaço social de construção de identidades e de políticas. Sanare, Sobral, n. 1, p. 39-42, 2003.

MONKEN, M.; BARCELLOS, C. O. Território na Promoção e Vigilância em Saúde. In: FONSECA, A. F.; CORBO, A. D'A. O território e o processo saúde-doença. Rio de Janeiro: EPSJV/Fiocruz, 2007. p. 177-224.

MONKEN, M.; BARCELLOS, C. O. Vigilância em saúde e território utilizado: possibilidade teóricas e metodológicas. Cadernos de Saúde Pública, Rio de Janeiro, v. 21, n. 3, p. 898-906, 2005. https://doi.org/10.1590/S0102-311X2005000300024

MÔRA, L. B. de et al. O uso de territorialização para apoio ao planejamento das ações de uma unidade de Saúde da Família. In: CONGRESSO BRASILEIRO DE POLITICA, PLANEJAMENTO E GESTÃO EM SAÚDE, 2., 2013, Belo Horizonte. Anais eletrônicos... Belo Horizonte: Abrasco, 2013. Disponível em: <http://www.politicaemsaude.com.br/ anais/trabalhos/publicacoes/198.pdf>. Acesso em: 18 abr. 2016.

MOYSÉS, S. T.; SÁ, R. F. da. Planos locais de promoção da saúde: intersetorialidade(s) construída(s) no território. Ciência \& Saúde Coletiva, Rio de Janeiro, v. 19, n. 11, p. 4323-4329, 2014. https://doi.org/10.1590/1413-812320141911.11102014

PEREIRA, M. P. B.; BARCELLOS, C. O Território no Programa de Saúde da Família. Hygeia, Uberlândia, v. 2, n. 2, p. 47-55, 2006.

RAFFESTIN, C. Por uma geografia do poder. São Paulo: Editora Ática, 1993.

SANTOS, A. L.; RIGOTTO, R. M. Território e territorialização: incorporando as relações produção, trabalho, ambiente e saúde na atenção básica à saúde. Trabalho, Educação e Saúde, Rio de Janeiro, v. 8, n. 3, p. 387-406, 2011. https://doi.org/10.1590/S1981-77462010000300003

SANTOS, M. Espaço e Método. São Paulo: Editora Nobel, 1985.

SILVA, A. M. R. et al. A Unidade Básica de Saúde e seu Território. In: ANDRADE, S. M.; SOARES, D. A.; CORDINI JÚNIOR, L. Bases da saúde coletiva. São Paulo: UEL-Abrasco, 2001. p. 145160.

SOUZA, M. J. L. O território: sobre espaço e poder, autonomia e desenvolvimento. In: CASTRO, I. E. de; GOMES, P. C. da C.; CORRÊA, R. L. (Org.). Geografia: Conceitos e Temas. Rio de Janeiro: Bertrand Brasil, 1995. p. 77-116.

UNGLERT, C. V. de S. Territorialização em Sistemas de Saúde. In: MENDES, E. V. Distrito Sanitário: O processo social de mudança das práticas sanitárias do Sistema Único de Saúde. São Paulo: Hucitec, 1993. p. 221-235. 